\title{
Sharing Learning Experiences through Correspondence on the WWW
}

\author{
Piet Kommers \\ Ass. Professor University of Twente, Faculty of Educational Science and Technology \\ Division of Educational Instrumentation; Box 217, \\ 7500 AE Enschede, The Netherlands \\ Tel. +31534893576 or 3611 Fax +31534894580 \\ kommers@edte.utwente.nl \\ http://www.to.utwente.nl/user/ism/kommers/personal.htm
}

\begin{abstract}
Asynchronous Learning Networks are the facilities and procedures to allow members of the learning communities to be more effective and efficient in their learning. One approach is to see how the 'sharing' of knowledge can be augmented through metadata descriptions attached to portfolios and project work. Another approach is to facilitate the reflection upon individual or collaborative learning experiences (Okamoto, Cristea, Matsui, \& Miwata, 2000). The position to be defended in my panel contribution is that both the metadata approach and the attempts to capture the students' meta-knowledge are rather complicated because of social and emotional reasons.
\end{abstract}

\section{Introduction}

The general awareness nowadays is that both broad- and narrow casting media provide significant support in the more tailored distribution of insight and understanding within and between learning communities, like in the statement below:

"All available instruments and channels of information, communications and social action could be used to help convey essential knowledge and inform and educate people on social issues. In addition to the traditional means, libraries, television, radio and other media can be mobilized to realize their potential towards meeting basic education need of all".

From: Final Report World Conference for All: Meeting Basic Learning Needs, Jomtien, 1990.

It may be clear that the communicative quality of WWWbased media is superior to one-way media like radio and TV. See also Girard (1990) and Burke (1990); many countries nowadays can still benefit a lot more if we tune radio program structures to the way students actually learn.

\section{Goal of the Discussion}

"Asynchronous Learning" implies that the sending and receiving co-students reside in a different learning phase and thus have an asymmetric added value like the tutor/tutee mechanism in collaborative learning. The problem in this situation is however that most of the students have the persistent idea that being a tutor means 'giving' and being a tutee means 'receiving'. This preconception paralyzes the synergy between potentially fruitful learning partners. That is why I will plead here for a less conventional mechanism in which the students informally support each other by sharing emotional and existential experiences. Some heterogeneity in course domain, prior knowledge, learning style or ethnic background may even be beneficial. So far the theories on cooperative- and collaborative learning have articulated its value for cognitive synergy between students with a certain complementary cognitive style or different prior knowledge. This is a definition that still fits in the instructional paradigm; expecting that students' learning is affected by the way they are confronted with information, the feedback and the further reconciliation with prior knowledge.

The underlying contribution to this ICALT panel is to claim that beyond the technology of asynchronous learning networks we need to articulate again the notions from social psychology that have been applied to face-toface education already the years before. For instance the humanistic-oriented definition of learning like: "Learning is the process whereby knowledge is created through the transformation of experience"; David Kolb (1984). One step further will take into account the situational and existential factors that determine the student as a real living person and the way this learning matches / interferes with his/her emotional and affective stage. Here the term "ecology of learning" fits well; It means that the cognitive, attitudinal, social and communicative factors should work together in order to provoke the right mentality for learning.

It is this time scale and granularity that demands for the right support from a "learning community". We may 
expect that students have significant study skills and knowledge consults to learn in an operational way; they have also acquired the needed memory strategies like for instance the LeiText method:

- Students learn autonomously and motivated

- They plan and actively integrate the learning outcomes in their habits and problem solving approach

- Teachers tend to coach the group process rather than the individual learning steps

- Both intellectual and competence progress is at stake

- Students are supposed to learn quicker and ever more flexible

The price for this shift into student autonomy is a higher moral- and existential pressure on the student as both the teacher and co-students have high expectations from the individual student; As in the more traditional settings the student could complain with the co-students about the unrealistic speed and the severe tests criteria, it is now the student him/her self who has invented the expedition. And it is even more problematic in learning projects where also the co-students are dependent from individual contributions; not to speak about the effects when students are finally grading each other's contributions.

\section{Directions for Solutions}

The time that project-oriented learning was a relief for one's individual responsibility is far behind; Teachers may start to show the more successful cases of previous years, and the learning group is often seen as an enterprise, competing with other groups. Through realistic cases learning is close to real labor organizations. The question is now how students can still recover from over ambitions and time stress

Two directions for solutions will be brought forward:

1. On-site learning communities should keep a high degree of informality with only a mature amount of competition and sufficient super-ordinate goals.

2. If this is not affordable because of an overstressed grading system, the student should find and relax in external WWW-based communication with students who belong to a different institute.

Though the first solution is inherently better, it might be inevitable to fall back on the second alternative. Here the communication serves a more emotional and personal function like consolation and regaining self-confidence. It is the more overall reflection on the link between studying and life itself that counts, and that is hardly reflected in the institutional context. Besides the direct learning community with students from the same institute it seems beneficial to join the larger www-based learning communities for the sake of existential support without any threat for repercussions in ones own institute.

An adjacent aspect is the teachers' learning network that should be apart from their employer or supervisor. It should lead to real partnerships between teachers who have doubts in progressing their skills. Here the importance is to have a low-threshold consultancy mechanism for external peer review and sharing experiences. Teachnet and the 21 st Century Teachers Network (21CT) are examples. However they have still a large accent on the provision of information like lesson models. The community aspects still have to be worked out. In fact the student and teacher network may have a lot in common.

\section{References}

- Kolb, D., Experiential Learning, Prentice Hall, Englewood Cliffs, NJ, 1984.

- Jomtien, 1990, http:/www.col.org/events/0006commradio.htm

- Burke, A. Communications \& Development: a practical guide. London: Department for International Development, 1999.

- Girard, B. Radio Broadcasting and the Internet: Converging for Development and Democracy. Voices, Journal on Communication and Development, December 1999. 3

- Okamoto, T., Cristea, A., Matsui, T., \& Miwata, T. (2000). Development and Evaluation of a Mental Model Forming Support ITS - the Qualitative Diagnosis Simulator for the SCS Operation Activity. Kinshuk, C. Jesshope, \& T. Okamoto (Eds.), International Workshop on Advanced Learning Technologies (IWALT 2000): Advanced Learning Technology: Design and Development Issues, Palmerston North, New Zealand, pp.137-140.: IEEE Computer Society. 